\title{
Readiness, acceptance and use of e-health systems in hospitals and health centers of North Western Ethiopia
}

\author{
Abinew Ali Ayele \\ ICT4D Research Center, Bahir Dar Institute of Technology, Bahir Dar University, Ethiopia
}

\begin{tabular}{l}
\hline \hline Article Info \\
\hline Article history: \\
Received Oct 23, 2019 \\
Revised Nov 17, 2019 \\
Accepted Dec 28, 2019 \\
\hline
\end{tabular}

\section{Keywords:}

Acceptance and use

Determinants

E-health systems

Health centers

Hospitals

Northwest Ethiopia

Readiness

\begin{abstract}
The purpose of this empirical study was to examine e-health readiness, acceptance and use in hospitals and health centers in Ethiopia. In this study, 900 samples were taken using a simple random sampling method from 10 Hospitals and 20 health centers in northwestern Ethiopia. SmartPls software was used for the structural equation modeling and path analysis techniques. All of the e-health readiness indicators, except employees' attitudes showed that hospitals and health centers were not ready to implement and use e-health systems. The intentions of users to accept and use e-health systems were evaluated and determinants were identified. Service quality from the technological factors, self-efficacy from the human factors and user training from the organizational factors were found to be significant determinants of user satisfaction, individual performance, and organizational performance respectively. Major determinants were an organizational performance with a contribution of $37.6 \%$ influence followed by an individual performance with $28.2 \%$ contribution (together accounted for about $65.8 \%$ influence) of the users' behavioral intentions to use e-health systems. The model, which explained $47.6 \%$ of the variances in the data, was found to be significant.
\end{abstract}

Copyright $(2020$ Institute of Advanced Engineering and Science. All rights reserved.

Corresponding Author:

Abinew Ali Ayele,

ICT4D Research Center,

Bahir Dar Institute of Technology,

Bahir Dar University, Bahir Dar, Ethiopia.

Email: abinewa@bdu.edu.et /abinewaliayele@gmail.com

\section{INTRODUCTION}

The advent of the rapidly advancing ICTs has changed the world to great extent. The development of the internet and the worldwide web have ensured the rapid growth and dominance of the digital era across the world. Technology is a key enabler to accelerate and improve productivity in all sectors [1]. The Healthcare sector is also transformed by advances in e-health [2]. E-Health offers the rich potential of sharing resources and supplementing the traditional healthcare delivery systems. It also enables the healthcare organization's ability to meet the needs of patients [3]. E-Health helps to enhance access to information and resources, to empower patients and to make informed about healthcare decisions, to streamline organizational processes and transactions, and provide improved quality of health services and patient satisfaction [4]. It is mainly, used to support the administration of patient and medicine data [5].

E-health is a broad term that describes the intersection of medical informatics, public health, and business to improve services in the healthcare industry through the application of the internet and related technologies. Besides, e-health encompasses the technical development, state-of-mind, a way of thinking, an attitude, and a commitment for networked, global thinking, to improve health care locally, regionally, and globally by using information and communication technology [6].

A study that assessed the e-health readiness of healthcare professionals in three selected government hospitals was conducted in North Gonder Zone of Ethiopia indicated low readiness and underutilization of e- 
health systems. Gender, age, computer literacy, computer-related skills, knowledge, good attitude, availability of computers, past information technology experience, availability of training, and complexity of the system were found the most determinant readiness factors of health care professionals [7].

Many e-health applications have been implemented in the Ethiopian healthcare sector. Health Management Information Systems (HMIS), Human Resource Information Systems (HRIS), Logistic Management Information system (LMIS), Electronic Health Management Information Systems (EHMIS), Electronic Medical Record (EMR) and TenaCare/SmartCare are some of the available systems. However, these systems are not efficiently utilized in the sector [6]. The work by [8] confirmed underutilization of health information is due to the lack of computer skills, knowledge, supportive supervision, and training [8]. In this study, e-health readiness factors, level of utilization and determinant factors of e-health systems acceptance and use in Ethiopian hospitals and health centers were empirically investigated.

\subsection{E-Health Readiness Assessment Framework}

Measuring the level of e-health implementation readiness requires a clear understanding of the key environmental components and their interactions. The main components to be examined are the people in the organization, the technology, and the organization itself. Therefore, the employees' technical skills, awareness and attitude, infrastructure, cultural change and technological readiness are the readiness index components to be evaluated [9]. The framework indicated in Table 1 and Figure 1 shows the readiness cutpoints [10].

Table 1. The Readiness scales and Indication of Means

\begin{tabular}{cl}
\hline Readiness Average Scores & \multicolumn{1}{c}{ Readiness Scale Level } \\
\hline $1.00-2.60$ & Not Ready needs a lot of work \\
$2.61-3.40$ & Not Ready needs some work \\
$3.41-4.20$ & Ready but needs a few improvements \\
\hline
\end{tabular}

Indicators were coded as $1=$ strongly Disagree, $2=$ Disagree, $3=$ Undecided, 4=Agree, and 5=Strongly Agree on a five-point Likert scale. The average score of 3.41 set as an expected level readiness cutpoint [10].

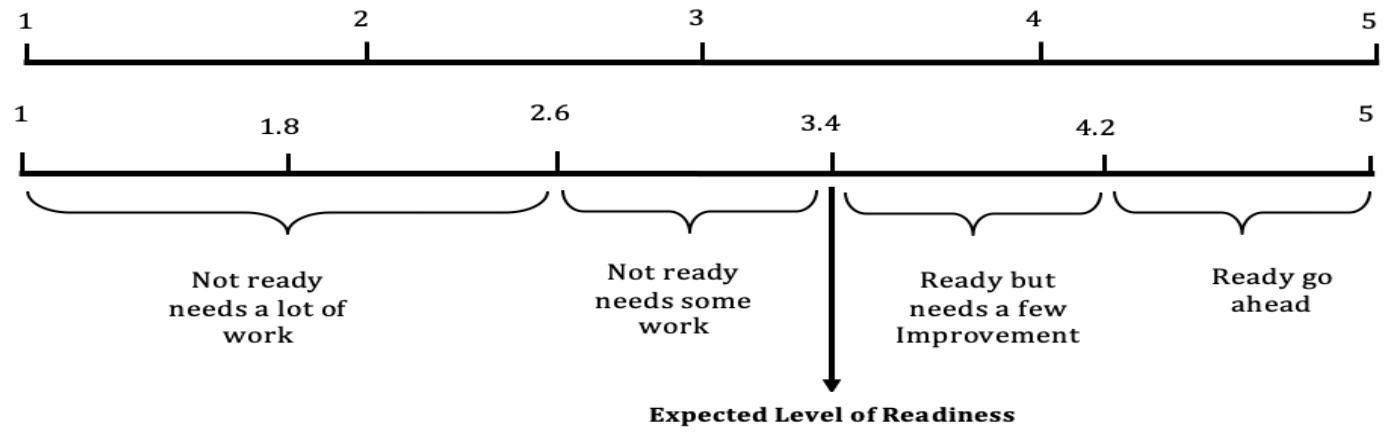

Figure 1. Readiness index framework [10]

\subsection{Acceptance and Use of E-health Systems}

Studies showed that the complexity and dynamics of the healthcare environment is a significant and inherent challenge for the successful adoption of e-health systems $[11,12]$. Hence, well understanding of ehealth implementation factors is an important step in the implementation process [13]. The failure of e-health systems is mainly due to the underestimation of the implementation factors and their interactions [11].

To ensure the successful adoption of new information systems, organizations must understand the three dimensions of the information system. These are described in the TOP Model (the organization, the people and the technology itself) as indicated in Figure 2 [12]. Moreover, the works by [14, 15] also confirmed people and technology-related factors determine the intention to adopt new information systems. 


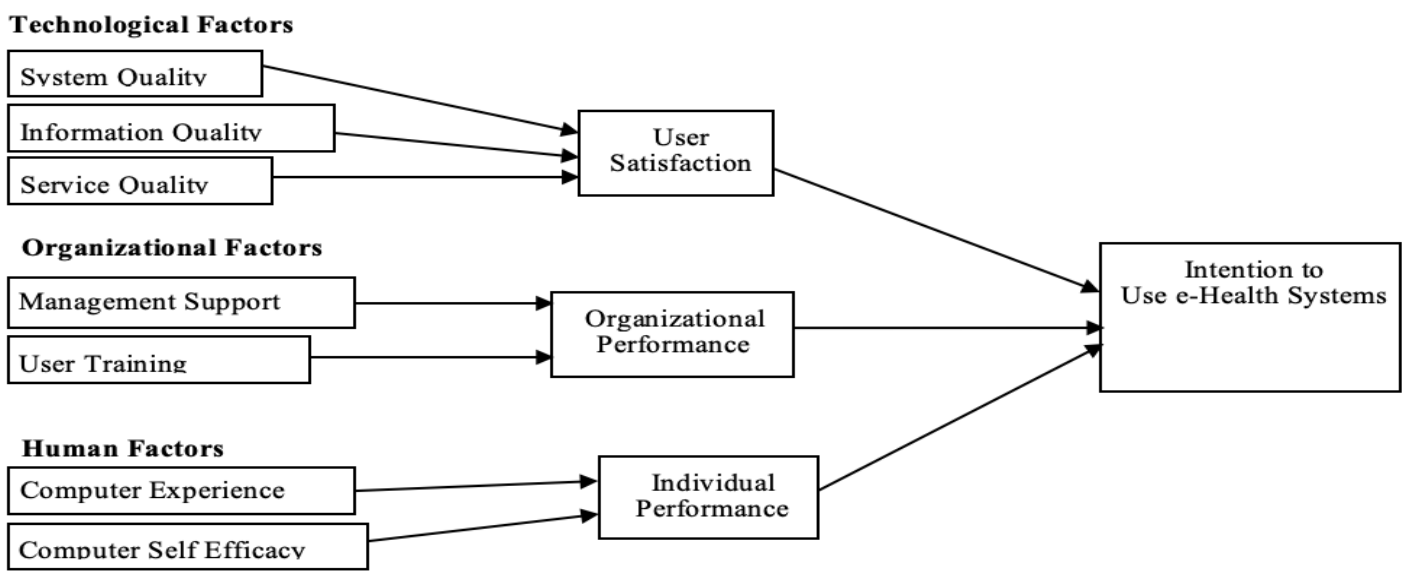

Figure 2. The research model

\subsubsection{The Technology Factor}

System quality, information quality, and service quality are the technological factors that influence the adoption of information [12]. The qualities of the technology itself, the quality of the information provided by the technology and the service that the technology renders affect user satisfaction and are crucial factors for successful adoption [9, 16]. A study conducted in Indonesia also confirmed that these three technological factors are decisive determinants of e-health acceptance and use [17].

\subsubsection{The Organizational Factor}

The support and commitment of the top management and user training are the organizational factors that influence the implementation of new information systems [12, 18]. The work by [17] confirmed top management support, User Training, user involvement and facilitating conditions are major organizational factors influencing e-health acceptance [17]. Another study conducted in Ethiopia showed that top management support and user training positively influence the acceptance and use of e-health systems [19].

\subsubsection{The People factor}

The people factor comprises computer self efficacy and users' experience [12]. Computer selfefficacy and users' computer experience positively influences e-health acceptance [17, 20].

In light of literature and empirical evidence reviewed so far, this study examined to what extent these factors (technology, organization and people) affect healthcare providers to accept, and use e-health systems in the Ethiopian healthcare environment.

\subsection{Research Hypotheses}

Based on the research model shown in Figure 1, the following research hypotheses were forwarded:

H1: Software quality positively influences user satisfaction in using e-health systems.

$\mathrm{H} 2$ : Information quality positively influences user satisfaction of using e-health systems

H3: Service quality positively influences user satisfaction of using e-health systems

H4: Management support positively affects organizational performance in using e-health systems

H5: User training positively influences the organizational performance of using e-health systems

H6: Computer experience positively influences the individual performance of using e-health systems

H7: Computer self efficacy positively affects individual performance of using e-health systems

H8: User satisfaction positively influences users' intention to use e-health systems

H9: Individual performance positively influences users' intention to use e-health systems

H10: Organizational performance positively influences users' intention to use e-health systems

\section{MATERIALS AND METHODS}

The goal of this investigation was to empirically examine the readiness, acceptance, and use of ehealth systems of healthcare providers in the Ethiopian healthcare environment. The study mainly employed a quantitative research methodology. Self-administered survey questionnaires were used to collect the research data. The size of the sample was determined using the formula [21] which is appropriate for finite populations. 


$$
n o=\frac{(z \alpha / 2)^{2} * p(1-p)}{\delta^{2}}
$$

Where: $\mathrm{N}=$ total population $\mathrm{n}=$ required sample size $\alpha=0.05=$ level of significant (Type-I error) $\delta=0.05$ which is the margin of error $\mathrm{P}=0.5$ for sample proportion of teachers

$$
\begin{aligned}
& n o=\frac{(1.96)^{2} * 0.5(1-0.5)}{(0.05)^{2}} \\
& n o=\frac{(3.84) * 0.5 * 0.5}{0.0025}=384.16=\mathbf{3 8 5} \\
& n=\frac{n o}{1+\frac{n o}{N}} \\
& n=\frac{385}{1+\frac{385}{35255}}=\frac{385}{1.011}=380.811=\mathbf{3 8 1}
\end{aligned}
$$

Even though 381 samples are representative enough based on the calculation, samples of 900 employees were taken from 10 government hospitals and 20 government health centers in the northwestern region of Ethiopia using a simple random sampling method. A cross-sectional survey study has been employed. The target population of the study was employees of hospitals and health centers in northwestern Ethiopia. SmartPLS 3 and SPSS (version 20) were used to build the PLS-SEM structural model (partial least regression structural equation model) and to analyze the descriptive approaches.

\section{RESULT AND DISCUSIONS}

\subsection{Socio-Demographic Characteristics}

From the 900 questionnaires distributed, 664 were collected indicating that the response rate was $73.8 \%$. From the collected 664 questionnaires, 543 (60.3\%) were found usable. The rest 121 questionnaires $(13.4 \%)$ were rejected, for either they were not properly filled or incomplete. This showed that the nonrespondent rate of the main survey was $22.2 \%$. The work by [22] indicated rates of responses greater than $50 \%$ are acceptable, $60 \%$ good, $70 \%$ very good, and $85 \%$ excellent for questionnaire survey methods. Therefore, the response rate of $73.8 \%$ in this survey was grouped under the very good category.

As shown in Table 2, Out of 543 respondents, 307 (56.5) of the respondents were males and the rest $236(43.5 \%)$ of the respondents were females. Regarding institution type, $285(52.5 \%)$ and $258(47.5 \%)$ of the respondents were taken from 10 hospitals and 20 health centers respectively.

Table 2. Respondents' Institution-Type, Number and Gender Information

\begin{tabular}{lcccc}
\hline & Number of & \multicolumn{2}{c}{ Gender } & \\
Institution type & Institutions & Male & Female & Total \\
\hline Health Center & 20 & 157 & 128 & 285 \\
Hospital & 10 & 150 & 108 & 258 \\
Total & 30 & 307 & 236 & 543 \\
\hline
\end{tabular}

As indicated in Table 3, 175 nurses, 35 medical doctors, 61 pharmacists, 88 laboratory technicians, 34 health information (HIT), 50 human resources, 66 procurement and finance, and 34 record office professionals participated in the survey. Concerning professional experience, the majority of the respondents $289(53.2 \%)$ had less than 5 years of experience followed by $178(32.8 \%)$ of respondents with 5-10 years of experience. Only (14\%) of the respondents had more than 10 years of experience.

As indicated in Figure 3, about $64.1 \%$ of the respondents were within the age category of 21-30 years old followed by $19.7 \%$ with the age category of 31-40 years old. These constituted $83.8 \%$ of the respondents were young adults. The rest $8.8 \%, 5.3$ and $2.0 \%$ were under age categories of less than 20, 41-51 and greater than 50 years respectively. This indicated that the majority of respondents were the youth and young adults. 
Table 3. Profession type and Professional Experience

\begin{tabular}{|c|c|c|c|c|c|c|c|}
\hline \multicolumn{8}{|c|}{ Professional Experience } \\
\hline Profession Type & Less than & $5-10$ & $11-15$ & $16-20$ & Greater than & & \\
\hline & 5 Years & Years & Years & Years & 20 Years & Count & Percent \\
\hline Nurse & 25 & 7 & 3 & 0 & 0 & 35 & $6.4 \%$ \\
\hline Medical Doctor & 28 & 24 & 8 & 1 & 0 & 61 & $11.2 \%$ \\
\hline Pharmacist & 40 & 33 & 13 & 0 & 2 & 88 & $16.2 \%$ \\
\hline Laboratory Technician & 29 & 4 & 1 & 0 & 0 & 34 & $6.3 \%$ \\
\hline Health IT & 26 & 14 & 7 & 3 & 0 & 50 & $9.2 \%$ \\
\hline Human Resource & 21 & 31 & 7 & 4 & 3 & 66 & $12.2 \%$ \\
\hline Finance \& Others & 19 & 13 & 2 & 0 & 0 & 34 & $6.3 \%$ \\
\hline Record Officer & 289 & 178 & 47 & 13 & 16 & 543 & $(100 \%)$ \\
\hline Count & 289 & 178 & 47 & 13 & 16 & 543 & $(100 \%)$ \\
\hline Percent & $53.2 \%$ & $32.8 \%$ & $8.7 \%$ & $2.4 \%$ & $2.9 \%$ & $100 \%$ & \\
\hline
\end{tabular}

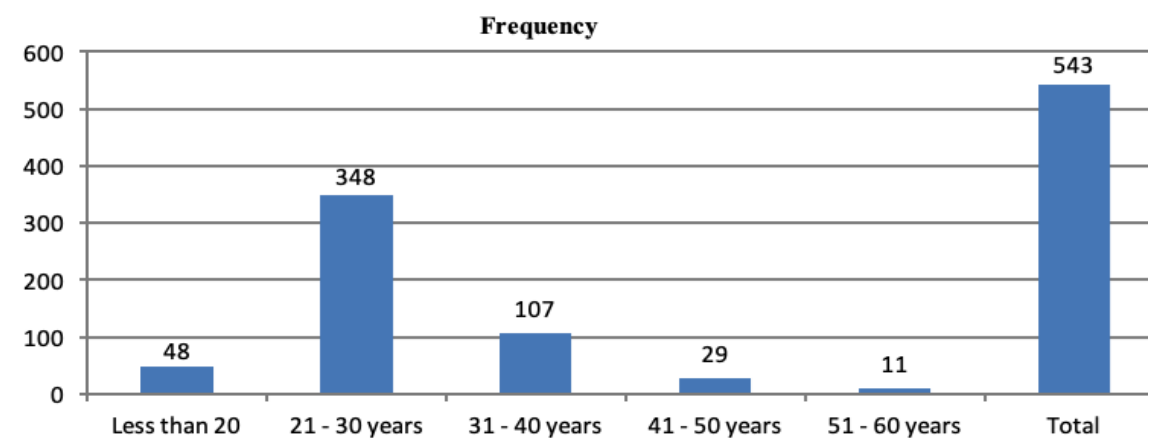

Figure 3. Respondents' age distribution

\subsection{E-Health Readiness constructs and Indicators}

A total of 17 readiness indicators were used in this study. These 17 indicators were grouped in six core readiness constructs of employees' technical skill readiness, awareness readiness, attitude readiness, infrastructure readiness, cultural change readiness, and technological readiness parameters. The means of each indicator, as well as the cumulative means of all constructs, were computed as shown in Table 4.

To measure the expected level of readiness, the average readiness level for each construct and indicator were computed. The results were compared against the expected level of readiness standards where 3.41 is the average expected level of readiness reference index [10].

As indicated in Table 4, the 3.28 average score of employees' technical skill readiness index was slightly lower than the expected level of readiness and implied that employees were not ready to use e-health systems, and they needed some support and work to get ready. The 3.08 average readiness index of employees' awareness about the use of e-health systems also indicated that employees were not ready to use e-health systems, and they needed some support and work to get ready.

The readiness of the institutions in terms of infrastructure, cultural change and technology had average scores of 2.22, 2.58 and 2.53 respectively. These scores were far less than the expected readiness. This indicated that institutions were not ready to accept and use e-health systems, and they needed a lot of work to get ready. On the other hand, Table 4 showed that attitude was the only construct that had an average readiness index value greater than the expected reference index. Hence, the employees' attitude average readiness index of 4.02 indicated that they were ready to accept and use e-health systems but still needs a few improvements.

\subsection{Acceptance and Use of E-health Systems}

In this study, 40 indicators were used to determine the acceptance and use of E-health systems. The partial least square structural equation modeling (PLS-SEM) technique was used to investigate the determinants of e-health acceptance and use in Ethiopian healthcare service. The reliability, validity, path coefficients and the model goodness of fit measures of the constructs were also computed.

The Cronbach's Alpha coefficient and composite reliability measures of each construct were greater than the minimum threshold value of 0.60 [23]. As shown in Table 5, the reliability of the major constructs in the model demonstrated a strong consistency of the responses except for the user satisfaction construct (0.57). The 0.95 overall reliability confirmed a strong consistency of the responses on the 40 indicators. 
Moreover, the AVE, convergent and divergent validities were between 0.68 and 0.86 for all constructs. These values were far greater than the 0.50 threshold and confirmed that the data could adequately describe the model [24].

Table 4. Average E-health Readiness Measures of Indicators and Constructs

\begin{tabular}{|c|c|c|c|}
\hline Readiness Constructs & Readiness Indicators & $\begin{array}{c}\text { Indicator } \\
\text { mean }\end{array}$ & $\begin{array}{c}\text { Construct } \\
\text { mean }\end{array}$ \\
\hline \multirow{3}{*}{$\begin{array}{l}\text { Employees' } \\
\text { technical skill }\end{array}$} & I have the basic skills to use computers & 3.47 & \multirow{3}{*}{3.28} \\
\hline & I have the basic skills to use the Internet & 3.48 & \\
\hline & I feel that I can use and operate any software application & 2.90 & \\
\hline \multirow[t]{2}{*}{ Employees' Awareness } & I have enough awareness about the importance of e-health systems & 3.05 & \multirow{2}{*}{3.08} \\
\hline & I have enough awareness about the availability of e-health systems & 3.10 & \\
\hline Employees' & I am happy to use the system in my job always. & 4.06 & \multirow[b]{2}{*}{4.04} \\
\hline \multirow[t]{2}{*}{ Attitude } & $\begin{array}{l}\text { I prefer to use e-health systems than traditional pen and paper methods in my } \\
\text { job }\end{array}$ & 4.02 & \\
\hline & I have has sufficient internet access in my institute. & 2.11 & \multirow{3}{*}{2.22} \\
\hline \multirow[t]{2}{*}{ Infrastructure } & The speed of the internet is sufficient enough to use the system & 2.17 & \\
\hline & I have sufficient access to computers & 2.36 & \\
\hline \multirow{5}{*}{$\begin{array}{c}\text { Cultural Change } \\
\text { Readiness }\end{array}$} & $\begin{array}{l}\text { My institute has clear policy and strategy to implement e-health software } \\
\text { applications }\end{array}$ & 2.58 & \multirow{3}{*}{2.58} \\
\hline & My institute has good culture and experience using new technologies & 2.61 & \\
\hline & The top management of my institute is always ready implement new changes & 2.60 & \\
\hline & The top management of my institute is committed to implement new changes & 2.52 & \multirow{4}{*}{2.53} \\
\hline & $\begin{array}{l}\text { Computers and related devices are sufficiently available to implement e-health } \\
\text { systems }\end{array}$ & 2.37 & \\
\hline \multirow[t]{2}{*}{ Technology } & My institute has local area network to implement e-health systems & 2.63 & \\
\hline & My institute has many e-health related software applications & 2.58 & \\
\hline
\end{tabular}

Table 5. Reliability and Validity of the Constructs

\begin{tabular}{lcccc}
\hline \multicolumn{1}{c}{ Indicator } & $\begin{array}{c}\text { Number of } \\
\text { Items }\end{array}$ & $\begin{array}{c}\text { Cronbach's } \\
\text { Alpha }\end{array}$ & $\begin{array}{c}\text { Composite } \\
\text { Reliability }\end{array}$ & $\begin{array}{c}\text { Average Variance } \\
\text { Extracted (AVE) }\end{array}$ \\
\hline Over all & 40 & 0.95 & -- & -- \\
Behavioral Intention & 3 & 0.90 & 0.94 & 0.83 \\
User Experience & 4 & 0.89 & 0.92 & 0.75 \\
Individual Performance & 4 & 0.92 & 0.95 & 0.82 \\
Information Quality & 4 & 0.90 & 0.93 & 0.77 \\
Organizational Performance & 4 & 0.93 & 0.95 & 0.83 \\
Self Efficacy & 4 & 0.92 & 0.95 & 0.81 \\
Service Quality & 4 & 0.95 & 0.96 & 0.86 \\
System Quality & 4 & 0.89 & 0.93 & 0.76 \\
Top Management Support & 4 & 0.94 & 0.96 & 0.86 \\
Training & 3 & 0.86 & 0.92 & 0.78 \\
User Satisfaction & 2 & 0.57 & 0.81 & 0.68 \\
\hline
\end{tabular}

\subsubsection{The Fornell-Larcker criterion}

The Fornell-Larcker criterion usually measures the degree of shared variance among the latent variables of the model. This criterion describes that, for any latent variable, the square root of average variance extracted (AVE) that appears in diagonal cells should be higher than its correlation with any other latent variable. The model is assumed to be good if the top numbers in any of the factor columns are higher than correlations below it. Therefore, as indicated in Table 6 , the model was found to be well fitted and good.

Table 6. Fornell-Larcker criterion

\begin{tabular}{llllllllllll}
\hline & BI & $\begin{array}{l}\text { User } \\
\text { Exp }\end{array}$ & $\begin{array}{l}\text { Ind. } \\
\text { Perf }\end{array}$ & $\begin{array}{l}\text { Info. } \\
\text { Qual }\end{array}$ & $\begin{array}{l}\text { Org. } \\
\text { Perf }\end{array}$ & $\begin{array}{l}\text { Self. } \\
\text { Eff }\end{array}$ & $\begin{array}{l}\text { Serv. } \\
\text { Qual }\end{array}$ & $\begin{array}{l}\text { Sw. } \\
\text { Qual }\end{array}$ & TMS & $\begin{array}{l}\text { User } \\
\text { Satis. }\end{array}$ \\
\hline BI & 0.912 & & & & & & & & & & \\
User Exp & 0.332 & 0.863 & & & & & & & & & \\
Ind.Perf & 0.631 & 0.423 & 0.903 & & & & & & & & \\
Inf.Q & $\mathbf{0 . 4 3 4}$ & $\mathbf{0 . 2 6 1}$ & $\mathbf{0 . 4 4 4}$ & $\mathbf{0 . 8 7 9}$ & & & & & & & \\
Org.Perf & 0.651 & 0.416 & 0.752 & 0.463 & 0.912 & & & & & \\
Serv.Q & 0.399 & 0.279 & 0.355 & 0.534 & 0.435 & 0.371 & 0.927 & & & \\
Sw.Q & 0.518 & 0.431 & 0.431 & 0.741 & 0.514 & 0.478 & 0.489 & 0.872 & & \\
TMS & 0.275 & ------0.071 & 0.320 & 0.162 & 0.283 & 0.114 & 0.236 & 0.079 & 0.926 & & \\
TR & 0.232 & 0.299 & 0.403 & 0.318 & 0.419 & 0.421 & 0.582 & 0.299 & 0.325 & 0.884 \\
U.Satis & 0.513 & 0.447 & 0.644 & 0.476 & 0.607 & 0.471 & 0.464 & 0.460 & 0.240 & 0.555 & 0.827 \\
\hline
\end{tabular}

Readiness, acceptance and use of e-health systems in hospitals and health centers of... (Abinew Ali Ayele) 


\subsubsection{Heterotrait-Monotrait Ratio (HTMT)}

Heterotrait-Monotrait Ratio (HTMT) also measures discriminant validity. In a better-fitted model, the Heterotrait correlations should be smaller than the monotrait correlations. As indicated in Table 7 , the HTMT ratios in this study were below the cutoffs $(0.85)$ and confirmed that the study meets discriminant validity [25].

Table 7. Heterotrait-Monotrait Ratio (HTMT)

\begin{tabular}{llllllllllll}
\hline & \multirow{2}{*}{ BI } & $\begin{array}{l}\text { User } \\
\text { Exp }\end{array}$ & $\begin{array}{l}\text { Ind. } \\
\text { Perf }\end{array}$ & $\begin{array}{l}\text { Info. } \\
\text { Qual }\end{array}$ & $\begin{array}{l}\text { Org. } \\
\text { Perf }\end{array}$ & $\begin{array}{l}\text { Self. } \\
\text { Eff }\end{array}$ & $\begin{array}{l}\text { Serv. } \\
\text { Qual }\end{array}$ & $\begin{array}{l}\text { Sw. } \\
\text { Qual }\end{array}$ & TMS & TR & $\begin{array}{l}\text { User } \\
\text { Satis. }\end{array}$ \\
\hline BI & & & & & & & & & & & \\
User Exp & 0.364 & & & & & & & & & & \\
Ind.Perf & 0.692 & 0.465 & & & & & & & & & \\
Inf.Q & 0.480 & 0.292 & 0.488 & & & & & & & & \\
Org.Perf & 0.710 & 0.455 & 0.808 & 0.505 & & & & & & & \\
Self.Eff & 0.457 & 0.549 & 0.521 & 0.376 & 0.443 & & & & & & \\
Serv.Q & 0.432 & 0.312 & 0.380 & 0.579 & 0.462 & 0.396 & & & & & \\
Sw.Q & 0.576 & 0.476 & 0.472 & 0.826 & 0.562 & 0.523 & 0.532 & & & & \\
TMS & 0.295 & 0.081 & 0.340 & 0.172 & 0.298 & 0.119 & 0.250 & 0.091 & & & \\
TR & 0.240 & 0.355 & 0.432 & 0.345 & 0.452 & 0.454 & 0.633 & 0.324 & 0.334 & & \\
U.Satis & 0.671 & 0.614 & 0.834 & 0.596 & 0.777 & 0.622 & 0.580 & 0.592 & 0.292 & 0.737 & \\
\hline
\end{tabular}

\subsubsection{Standardized Root Mean Square Residual (SRMR)}

The standardized root means square residual (SRMR) measures the research model's goodness of fit. SRMR determine the discrepancy between the observed correlation matrix and the model implied correlation matrix by measuring the approximate fit of a research model. A model has a good fit when the SRMR value is less than 0.08 [24]. Therefore, the SRMR value of 0.056 was below the cutoff (0.08). As shown in Table 8, the T-statistics greater than 1.96 and $\mathrm{P}$ value less than 0.05 in this study confirmed that SRMR was significant.

Table 8. Standardized Root Mean Square Residual (SRMR)

\begin{tabular}{ccc}
\hline SRMR & T-Statistics & P-value \\
\hline 0.056 & 18.168 & 0.000 \\
\hline
\end{tabular}

\subsubsection{The Path Coefficients and Model Goodness of Fit}

R-square (coefficient of determination) measures the overall effect size structural model. R-square values greater than the cutoffs $0.67,0.33$, and 0.19 were categorized as substantial, moderate, and weak, respectively [23]. Table 9 presented R-square, T-statistics, P-value of Behavioral Intention of users. The $0.476 \mathrm{r}$-square in this study classified in the second category, which was moderate. Moreover, the $\mathrm{T}$ statistic values greater than 1.96 and $\mathrm{P}$ values less than 0.05 for $\mathrm{r}$-square indicated that the model was significant.

Table 9 R-Square

\begin{tabular}{cccc}
\hline & R Square & T-Statistics & P-value \\
\hline Behavioral Intention & 0.476 & 7.728 & 0.000 \\
\hline
\end{tabular}

As indicated in Figure 4 and Table 10, the path coefficients of independent constructs demonstrated different contributions to the dependent construct (behavioral intention to use e-health systems). Software quality, information quality, and service quality were the factors that determined user satisfaction to use ehealth systems. Self-efficacy and computer experience were the factors that determined individual performance to use e-health systems. Top management support and user training were also the factors that determined organizational performance to use e-health systems. Besides, organizational performance, individual performance, and user satisfaction were significant determinants of behavioral intention that affect e-health systems use. The T statistics values above the cutoff (1.96) and the P values below 0.05 for all path coefficients were significant, as indicated in Table 10. 
Table 10. Path Coefficients

\begin{tabular}{lccc}
\hline \multicolumn{1}{c}{ Path } & Path Coefficient & T Statistics & P Values \\
\hline Computer Experience $\rightarrow$ Individual Performance & 0.243 & 2.737 & 0.006 \\
Individual Performance $\rightarrow$ Behavioral Intention & 0.282 & 1.834 & 0.067 \\
Information Quality $\rightarrow$ User Satisfaction & 0.197 & 1.620 & 0.106 \\
Management Support $\rightarrow$ Organizational Performance & 0.164 & 2.460 & 0.014 \\
Organizational Performance $\rightarrow$ Behavioral Intention & 0.376 & 2.553 & 0.011 \\
Self Efficacy $\rightarrow$ Individual Performance & 0.362 & 3.739 & 0.000 \\
Service Quality $\rightarrow$ User Satisfaction & 0.270 & 3.514 & 0.000 \\
System Quality $\rightarrow$ User Satisfaction & 0.182 & 1.523 & 0.129 \\
User Satisfaction $\rightarrow$ Behavioral Intention & 0.103 & 1.116 & 0.265 \\
User Training $\rightarrow$ Organizational Performance & 0.366 & 5.586 & 0.000 \\
\hline
\end{tabular}

As shown in Figure 4 and Table 10, software quality, information quality and service quality positively contributed $18.2 \%, 19.7 \%$ and $27 \%$ to user satisfaction respectively. Self-efficacy and computer experience also positively contributed $36.2 \%$ and $24.3 \%$ on an individual's performance. Besides, top management support and user training positively contributed $16.4 \%$ and $36.6 .3 \%$ influence on organizational performance. Service quality, self-efficacy and training were significant determinants of user satisfaction, individual and organizational performances respectively. Hence, hypotheses H1, H2, H3, H4, H5, H6, and H7 were accepted.

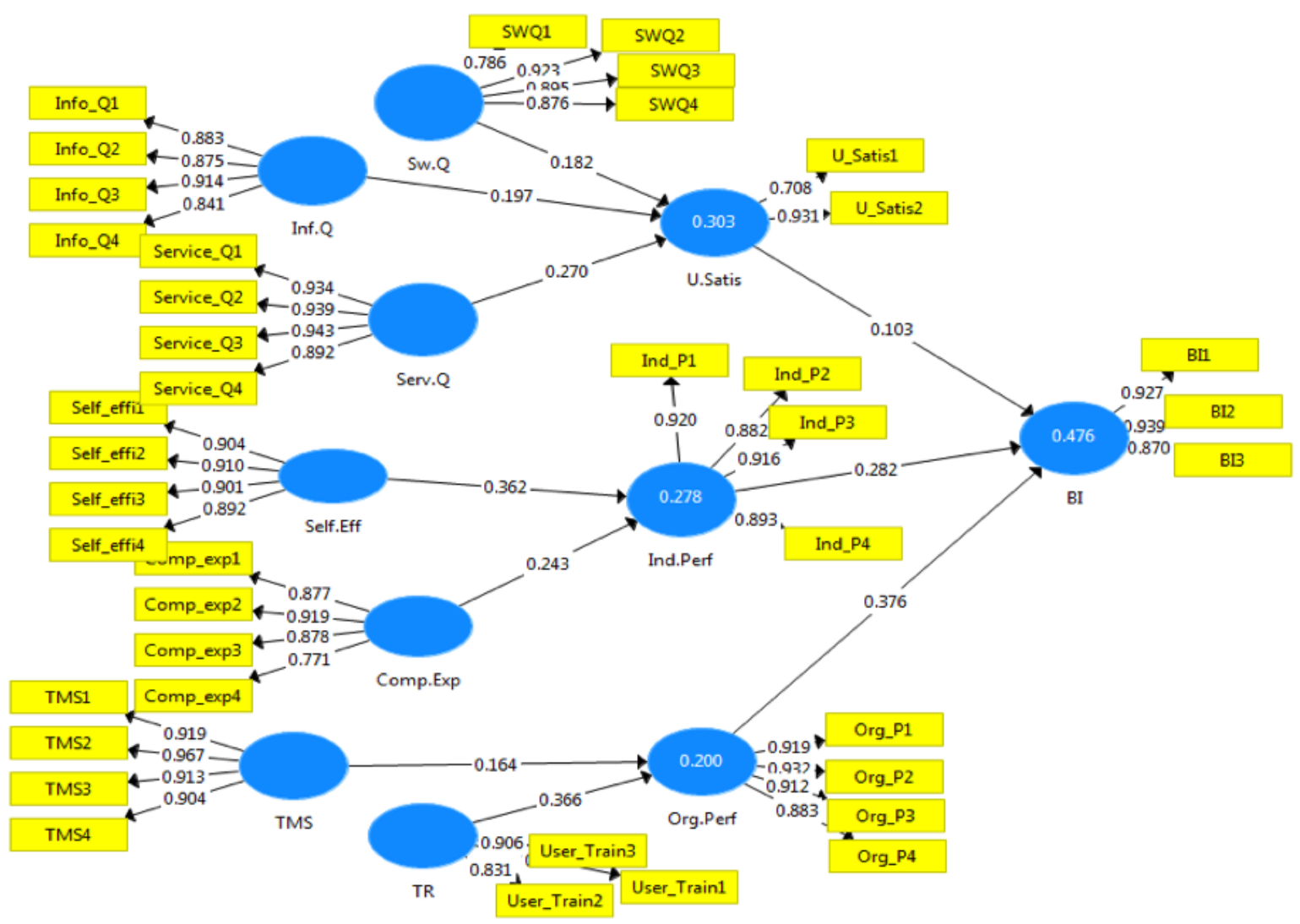

Figure 4. PLS-SEM structural model result

The positive path coefficient of $10.3 \%$ of user satisfaction in Table 10 indicated that the inclinations of e-health system users were due to user satisfaction. Hence, user satisfaction alone accounted for $10.3 \%$ contribution to the behavioral intention of users and hypothesis H8 was accepted. An individual's performance demonstrated a positive contribution of $28.2 \%$ alone to the behavioral intention of e-health system users. Therefore, hypothesis H9 was accepted. Organizational performance demonstrated a $37.6 \%$ positive contribution alone to behavioral intention of e-health system users. Hence, hypothesis H10 was accepted. 


\section{CONCLUSIONS AND RECOMMENDATIONS}

E-health systems are critically important to support and improve the overall healthcare delivery systems. The findings showed hospitals and health centers were not ready to implement and use e-health systems since all readiness indicators except employees' attitudes were under the readiness index cutpoint. Service quality from the technological factors, self-efficacy from the human factors and user training from the organizational factors were significant determinants of user satisfaction, individual and organizational performances respectively. Hence, understanding the healthcare environment and regularly assessing the situations before e-health implementation is critically important for success. This study can be taken as a benchmark for further research concerning the readiness, acceptance, and use of e-Health Systems in hospitals and health centers at the national level. The study can also be extended with other technology adoption models like UTAUT, So-UTAUT as well as methods like PLS-SEM and CB-SEM to better understand other dimensions related to e-health systems.

\section{REFERENCE}

[1] Hamiz M, Bakri M, Kamaruddin N, Mohamed A. "Assessment Analytic Theoretical Framework Based on Learners' Continuous Learning Improvement.” Indonesian Jour. of Electrical Eng and Comp. Science. 2018 Aug;11(2):682-7.

[2] Narassima MS, Anbuudayasankar SP, Vasudevan SK, Abhinavaram J. "Physicians and Users Perceptions Towards Wearable Health Devices.” Indonesian journal of electrical engineering and computer science. 2017; 5:234-42.

[3] V. M. Kiberu, M. Mars, and R. E. Scott, "Barriers and opportunities to implementation of sustainable e-Health programmes in Uganda: A literature review," African J. Prim. Heal. Care Fam. Med., vol. 9, no. 1, 2017.

[4] D. H. Mehmood et al., "Electronic Health Record Systems; Perception and Evaluation Among Physicians in Pakistan," Prof. Med. J., vol. 24, no. 01, pp. 182-187, 2017.

[5] Nugraha DC, Aknuranda I. "An Overview of e-Health in Indonesia: Past and Present Applications.” International Journal of Electrical \& Computer Engineering (2088-8708). 2017 Oct 1;7(5).

[6] Oh H, Rizo C, Enkin M, Jadad A. "What is eHealth (3): a systematic review of published definitions." Journal of medical Internet research. 2005;7(1):el.

[7] Biruk S, Yilma T, Andualem M, Tilahun B. "Health Professionals' readiness to implement electronic medical record system at three hospitals in Ethiopia: a cross sectional study." BMC med. Inf. and dec. making. 2014 Dec; $14(1): 115$.

[8] Asemahagn MA. "Determinants of routine health information utilization at primary healthcare facilities in Western Amhara, Ethiopia." Cogent Medicine. 2017 Jan 1;4(1):1387971.

[9] Al-Nidawi WJ, kamil Jaafar al-wassiti S, Maan MA, Othman M. "A review in E-government service quality measurement." Indonesian Journal of Electrical Engineering and Computer Science. 2018 Jun 1;10(3):1257-65.

[10] Aydin CH, Tasci D. "Measuring readiness for e-learning: Reflections from an emerging country." Journal of Educational Technology \& Society. 2005 Oct 1;8(4):244-57.

[11] Hage E, Roo JP, van Offenbeek MA, Boonstra A. "Implementation factors and their effect on e-Health service adoption in rural communities: a systematic literature review." BMC health services research. 2013 Dec;13(1):19.

[12] Al-Mamary YH, Shamsuddin A, Hamid A, Aziati N. "Investigating the key factors influencing on management information systems adoption among telecommunication companies in Yemen: the conceptual framework development." International Journal of Energy, Information and Communications. 2015;6(1):59-68.

[13] Yusof EM, Othman MS, Yusuf LM, Kumaran SR, Yusof AR. "A model of acceptance factors for business intelligence in manufacturing using theoretical models." Indonesian Jour. of E.E. \& C.S. 2019 Jun 1;14(3):154451.

[14] Busu S, Karim NA, Haron H. "Factors of adoption intention for near field communication mobile payment." Indones J Electr Eng Comput Sci. 2018 Jul;11(1):98-104.

[15] R.R. Ikram,L. Salahuddin, M.H M. Naim, A. Idris, N.A.Z Abidin, N. Ishak, and N.R.A Hamid, “A conceptual integrated health information systems framework in postnatal care for modern and traditional Malay medicine." Indonesian J Elec

[16] Delone WH, Mclean ER. "The DeLone and McLean Model of Information Systems Success : A Ten-Year Update." Journal of management information systems. 2003 Apr 1;19(4):9-30.

[17] Purnawati NW, Setyohadi DB, Suyoto S. "Investigation of E-Health Acceptance Factor." Jurnal Infotel. 2018 Jul 5;10(2):45-55.

[18] Ahmad NA, Drus SM, Bakar NA. "Enterprise architecture adoption issues and challenges: A systematic literature review." Indonesian Journal of Electrical Engineering and Computer Science. 2019 Jul 1;15(1):399-408

[19] Ayele AA, Birhanie WK. "Acceptance and use of e-learning systems: the case of teachers in technology institutes of Ethiopian Universities." Journal of Applied Informatics 2018 Dec (Vol. 5, No. 1, p. 1). SpringerOpen.

[20] Li J, Talaei-Khoei A, Seale H, Ray P, MacIntyre CR. "Health care provider adoption of eHealth: systematic literature review." Interactive journal of medical research. 2013;2(1):e7.

[21] Cochran WG. Sampling Techniques. John Wiley \& Sons. New York. 1977.

[22] McColl E, Jacoby A, Thomas L, Soutter J, Bamford C, Steen N, Thomas R, Harvey E, Garratt A, Bond J. "Design and use of questionnaires: a review of best practice applicable to surveys of health service staff and patients." Core Research; 2001. 
[23] Chin WW. "The partial least squares approach to structural equation modeling. Modern methods for business research.” 1998 Jan;295(2):295-336.

[24] Hu LT, Bentler PM. "Fit indices in covariance structure modeling: Sensitivity to underparameterized model misspecification.” Psychological methods. 1998 Dec;3(4):424.

[25] Clark LA, Watson D. "Constructing validity: Basic issues in objective scale development. Psychological assessment." 1995 Sep; 7(3):309.

\section{BIOGRAPHY OF AUTHORS}

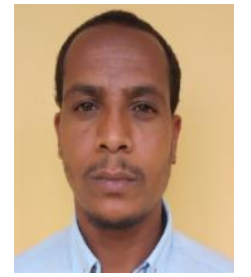

Abinew Ali Ayelereceived BscDegree in Information Technology and MSc degree in Information Science from Addis Ababa University in 2005 and 2010 respectively. He is a researcher and EService Research Group Head in ICT4D Research Centre, Bahir Dar University. He is also woking as a senior lecturer in the faculty of Computing, Bahir Dar Institute of Technology, Bahir Dar University. He has three published works in the area. 